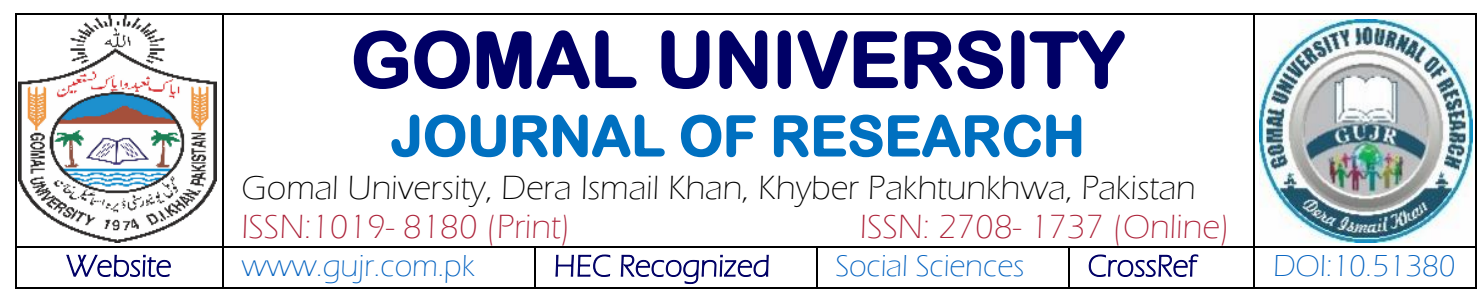

\title{
AN INVESTIGATION ON ROLE OF STRESS ON ACADEMIC PERFORMANCE OF STUDENTS
}

\author{
Yasir Hayat Mughal \\ Department of Health Administration, College of Public Health and Health Informatics, Qassim \\ University, SAUDI ARABIA
}

\section{\begin{tabular}{l|l}
\hline KEYWORDS & ABSTRACT
\end{tabular}}

Stress, Performance,

Environmental, Social,

Personal \& Academic

Factors, Students

\section{Article History}

Date of Submission:

02-07-2021

Date of Acceptance:

16-09-2021

Date of Publication:

30-09-2021
The purpose of the study is to investigate the role of stress upon academic performance of students. Stress is faced by each individual in academic, professional as well as daily routine life. The current study has identified different sources of stress which might be controlled to enhance academic performance of students. For this purpose cross-sectional design survey approach was conducted from two different universities from the different faculties. The development of scientific knowledge in current study is based on the positivism philosophy. The non probability convenience sampling technique was used. Population of the study was students from public and private universities. 210 students have participated in the study. Cronbach alpha, correlation and regression were used for analysis of data. SPSS 25 was used. Findings of study revealed that scale adopted from past studies was found reliable and there is significant positive relationship between factors of stress and academic performance of students. It was also found that academic factors were most dominant factors which played significant role in affecting students' performance. This study is original contribution and has extended the body of knowledge of stress and student academic performance.

\section{(c) (9) \&}

2021 Gomal University Journal of Research

Corresponding Author

Yasir Hayat Mughal: y.hayat@qu.edu.sa

$\mathrm{DOl}$

https://doi.org/10.51380/gujr-37-03-04

\section{INTRODUCTION}

When a person, an individual does not have capability to cope with or handle some situation, condition or event is called stress. Something which is beyond the capacity of an individual is also called stress (Chen \& Baram, 2016). Limited is known by the individuals about stress and its factors. It is complex and difficult phenomenon it could be started at workplace, educational institute or in daily life. In the same way students from start of their early education till higher education at universities faced different styles of teaching. Every teaching style and subject has its own demand to complete course and degree and it is great source of stress among students. Students faced physical, emotional, social, family issues as well as uncertainty about future and 
pressure of academics. Students are over burdened with new duties, assignments, presentation, quiz, mid exams and final exam (Kotter, Wagner, Bruheim \& Voltmer, 2017). The low academic performance is the main problem of current study and the existing study has tried to identify the predictors which are responsible for affecting performance of students. Stress could lead to other possible mental health issues like depression, anxiety, hypertension, sleeping disorder, emotional exhaustion and burnout. In this linking, these would have negative influence on the health of students. Therefore, it is essential to carry out this study and report the problems of the students and how to solve these problems is the main issue of the study. In this connection, it is reported that those students who have lot of stress have negative and bad impact on their academic performance. Thus, these students have low quality of life (Pascoe, Hetrick \& Parker, 2020).

College and universities environments are different, their teaching styles and demands of teachers are different, and therefore these factors have influence upon students' level of stress. Students must be given orientation about atmosphere, culture of educational institutes. Students must be aware of new relationship with teachers and class fellows they must be given training and orientation about how to graduate on time (Hamaideh, 2011). Students face stress at different stages in their academic career life most important factors are psychological meaningfulness which means that rich in physical and mental health. Second one is individuals control their inner states and conditions through their external situations such as demands. As per Ogden (2004) a common person or an individual got stress forms external forces, unpleasant moment, anxiety, depression emotional reaction. In this connection, these are certain factors which are found dominant playing their role and negatively affecting academic performance and mental health of universities' students. In this linking, this study has emphasized this issue and tried to fill the gap in the literature of the stress and student academic performance. Consequently, the current study aimed is to find the most dominant factor or stressors which are responsible for increasing the stress among students and negatively affect performance (Lin, Zhang \& Yang, 2020).

\section{Problem Statement}

Stress is the main issue among students nowadays and it forbids the students to actively engage themselves in attaining knowledge and actively taking part in learning activities. It is the most important issues in academic institutions and one cannot enjoy the fruits of their capabilities due to high level of stress (Hamaideh, 2011). Stress has been identified and reported as main problem among students and it is considered as obstacle between students and their excellent academic performance. According to the best of researcher's knowledge limited knowledge is available on stress among universities students so far. This study has tried to highlight factors which are barriers to academic performance. The future of any country especially developing economies lies in the hands of their youth because they are considered as the future leaders (Chen \& Baram 2016). So, students could take benefits from findings of current study as well as administration of universities can take benefits from study findings. Parents and stakeholders can take benefits and can arrange meetings with administration of universities and seminars and workshops might be arranged to give students awareness about stress and how to control it or reduce it.

\section{LITERATURE REVIEW}

Students got shock when they are transferred from school life to college or university life. Due to change in teaching environment, teaching system and methods, new requirements, relationship 
with new faculty members and new class fellows have the great influence upon the stress and students' mental health and academic performance (Hussein, Alhareth, Abu-Salih, Muhammad \& Saket, Lubna 2016). There are different factors of stress have been identified by academicians and researchers like overcrowded classrooms, competition among students of same university or other universities, negative relationship with the faculty members and class fellow, lack of pocket money, family issues, and fear of failure (Harris, Wilson \& Hughes, 2018). Thus, this section provides existing literature on the issues under considerations to understand the issues comprehensively.

\section{Academic Stress}

Stress can be defined as "when an individual has faced some disease due to some pressure is called stress. The relationship among an individual and environment in which s(he) is living which endangers the life of a persons' welfare is called stress. Academic pressure means when demands of the subject/course exceeds the capabilities of students. Work load, social pressure, time control, fear of failure, semester time, reduction in self-worth are the considered as main factors of stress (Laurence, Williams \& Eiland, 2009; Britz \& Pappas, 2010). Going to university to get higher education is dream of many students and most of students enjoy their university life but on same time it is source of stress for few students. Academic requirements to achieve excellent performance is based on quiz, tests, presentations, assignments, class presentations, midterm/semester and final semester exams. It is claimed in the past studies that when child get mature emotionally and psychologically it is also responsible and contribute towards stress among child/students. Another cause of stress among students is continuously decreased in parental care, love and affection also increases the stress level among students. When a child reaches to puberty stage there is some change in physical and psychological structure of the child.

\section{Sources of Stress}

Sources of stress are known as stressors. Change in life styles such as unemployment, chronic disease, week financial situation, overcrowded homes is causes of stress. Every one face stress in the daily life but there are five sources of academic stress which are explained in this study as follows, personal factors, social factors, environmental factors academic factors (Pascoe et al., 2020).

\section{Personal Factors}

According to Bhargava and Hemant (2018), the university students are conscious about their physical structure, they want to have expensive clothes, good body structure, degrading them and comparing with others, dissatisfaction from the lifestyle is a great source of stress. Those families who have conflicts among each other constantly due to lack of communication between parents and child, and no care of other expectations is a cause of stress in different situations. In this connection, too much expectations from each other, expecting high salary job, comparing one's own child with others' is one of the reason of stress among students and it affects their mental health and outcomes. Relatives play their important role in increasing mental issues of a student.

\section{Social Factors}

Social stress can be defined as an uncomfortable situation at social places faced by individuals is called social stress or undesirable and problematic roles played by individuals in daily social 
life is called social stress (Wadman, Durkin \& Ramsden, 2011). With the increase in civilization and increase in number of human beings in societies, people have to play more roles; some play positive while other plays negatives roles at the same time we can see some people who remain neutral. We can categorize these roles in to two categories one at workplace and one at home it means professional and personal life. In professional life people play role of colleagues, leaders, managers boss, subordinate while at home one might be husband, wife, brother, sister, father and mother. So, stress is everywhere in daily life either professional or personal. It was observed that some students play dual role as student as well as working in organizations. A student who does not afford to pay semester fee have to work and need to adjust with education institutions in start of first years. Students have many reason to work during study for example death of parents, social and financial obstacles. when students work at night they do not have enough time to study. This may lead to lower their grades and effect significantly upon their academic performance.

\section{Environmental Factors}

Stress in human being is universal, it uses the fuel of the human body to meet the issues and solve them. Major events of the life are related with changes in life events and hurdles in life. There are several internal and external factors which directly effects the stress in human beings. Students when got admissions in the new education institution are worried about their choice making, new relationships, and degree requirements. In this connection, the stress might be produced due to the numerous factors like distance from the home, home sickness, working in other cities, lack of the medical facilities, lack of vacations, extreme weather etc (Hussein et al., 2016).

\section{Academic Factors}

Education is one of the main reasons of stress among pupils. Behavior of the teacher, lack of interest in particular subject, less time for preparation of assignments and quiz are the main reasons of stress among students. Parents and teachers only measure students' performance by comparing academic achievements in semester. This may cause to increase in stress among students. Expectation from parents, teachers and societies are also one of the main reasons of stress among students in universities. Students associated their future jobs with their current grades this is also one of the reason of stress. Few students due to fear of fail in the exam work very hard and this is reason of their success. Among factors of stress there is another factors which may cause depression among students is tension after exam. The student starts thinking and comparing their test scores with their counterparts. Taking too many courses to graduate on time can cause students mentally, socially, emotionally psychologically unstable (Kotter et al., 2017).

\section{Selye's Theory}

He was first person to introduce this syndrome in medical field i.e. stress. He defined this stress as symptoms those are non specific could to lead to illness. Selye explained that stress continue to remain in person for entire period till exposure to unspecific demand. He called his research a stress syndrome. Further, he divided stress into three categories one is alarm, resistance and exhaustion.

\section{Hypotheses Development}

Stress is universal. Both male and female students face stress at academic institutions. Both genders face problems in preparing tests, quiz, mid and final term exams, shortage of time for 
assignments and presentations. Thus, both genders and their academic performance could be affected by social, personal, environmental and academic factors. There is relationship with stress and academic performance. On the basis of above discussion following hypotheses are developed:

$\mathrm{H}_{1}$ : There is significance relationship amid factors of stress \& students academic performance. $\mathrm{H}_{2}$ : There is significant effect of the factors of stress on the students' academic performance.

Figure 1 Theoretical Framework

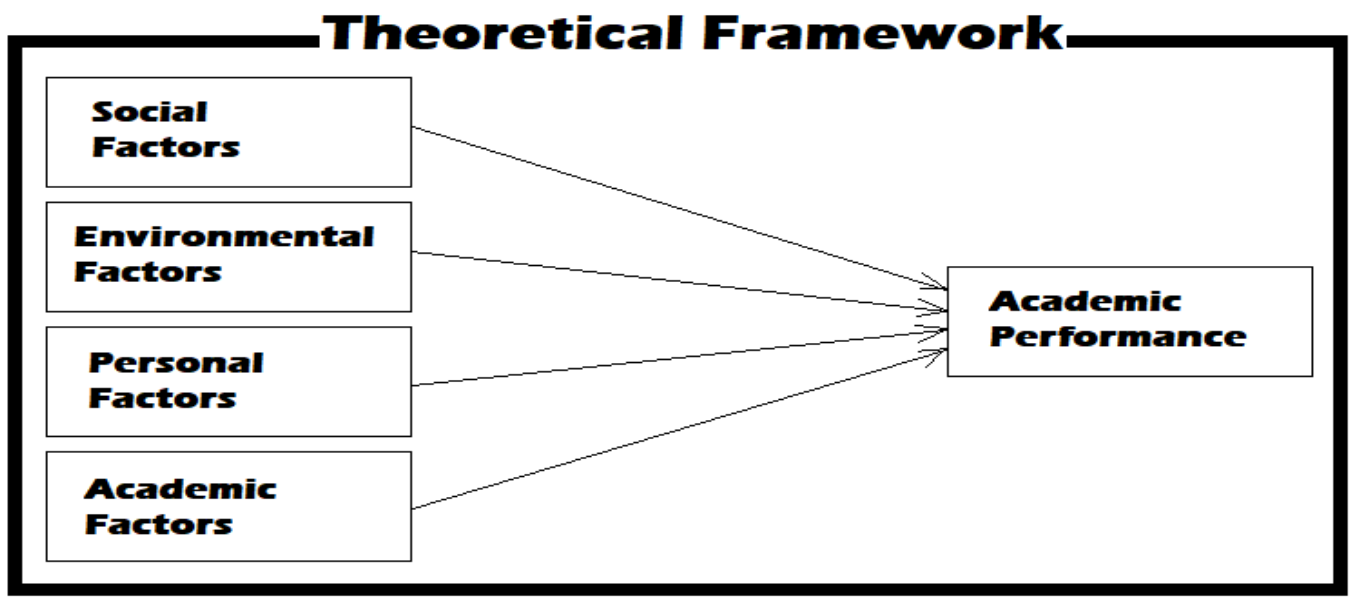

\section{RESEARCH METHODOLOGY}

The methods and porocedures for conducting the research have been presented in this section. This study used the positivist approach as positivism philosophy suggested for the development of scientific knowledge for current study by using different tools and teachiniques to reach the conclusion.

\section{Research Design, Population \& Sampling}

The current study has used survey approach design. Advantage of the survey approach is lower cost; less time is required and needed for the collection of large data from big population. The structured questionnaire was used. The questionnaire comprised of two sections. One section was consists of demographic variables while other include of social, personal, environmental and academic factors. All items were measured on five point likert scale ranging from 1-5, strongly disagree to strongly agree ten Items for construct. Total 40 items questionnaires were distributed. Two items from social factors items number 2 and 3 were deleted because of low ITC values. Total questions remained for analyses were 38. Students from 1 public and 1 private university were selected as participants of study. Non probability convenience sampling technique was used. Primary data was collected and nature was cross-sectional. It means data was collected at single time.

\section{Data Collection \& Analysis Technique}

SPSS version 25 was used for data analysis. Total 210 students have participated in the current study. Questionnaires were given to students after getting permission. After explaining the aim 
of the study to students were given 3-4 days to complete the survey. Descriptive and inferential statistics was sued to test hypotheses. Reliability was checked over cronbach alpha. For testing hypotheses correlation and t-test, ANOVA were used. The range of cronbach alpha is $0-1$, alpha is acceptable at 0.7 , while cronbach alpha at 0.8 is considered very good. And 0.9 is considered excellent.

\section{Research Ethics}

Ethics were taken into consideration. All respondents were made assure that their identity and data would be kept confidential and it will not harm reputation of organizations nor individuals. 3-4 days were provided to respondents so that they may be able to understand and provided relevant response.

\section{RESULTS OF STUDY}

The results of present study have been offered in this section as the outcomes of the statistical procedures.

Table 1

Reliability and Validity Analysis

\begin{tabular}{llll}
\hline Variables & Constructs & Items & Cronbach Alpha \\
\hline \multirow{3}{*}{ Sources of Stress } & Social factors & 8 & \\
& Personal factors & 10 & 0.864 \\
& Environmental & 10 & \\
\hline & Academic & 10 & \\
\hline
\end{tabular}

Reliability of questionnaire was investigated through item total correlation and cronbach alpha. The criteria for ITC and cronbach alpha was suggested by Field (2013). ITC values less than 0.4 were excluded from analysis as they are considered as problematic items and significantly affected the overall reliability of scale. Two items of social factors item number 2 and 3 were excluded because of low ITC values. Overall alpha value of scale is 9.864 this is considered as very good. According to Tabachnik and Fidell (2007) alpha value of 0.4 is not acceptable, 0.5 is considered as poor, 0.6 is questionable and 0.7 is acceptable. 0.8 is very good and above 0.9 is excellent.

\section{Table 2}

Correlation Analysis

\begin{tabular}{|c|c|c|c|c|c|c|}
\hline Variables & Mean & S.D & 1 & 2 & 3 & 4 \\
\hline Academics & 3.77 & 0.57 & 1 & & & \\
\hline Environmental & 3.41 & 0.63 & $.452^{* *}$ & 1 & & \\
\hline Social & 3.12 & 0.66 & $.539 * *$ & $.516^{* *}$ & 1 & \\
\hline Personal & 2.97 & 0.70 & $.465^{* *}$ & $.501^{* *}$ & $.613^{* *}$ & 1 \\
\hline $\mathrm{AP}$ & 3.45 & 0.56 & $.982^{* *}$ & $.488^{* *}$ & $.588^{* *}$ & $.503^{* *}$ \\
\hline
\end{tabular}

Above table 2 reveals results of correlation analysis. It was revealed that relationship between academic stress and academic performance was $\mathrm{r}=0.982, \mathrm{p}<0.05$, while relationship between environmental stress and academic factors is $\mathrm{r}=0.488, \mathrm{p}<0.05$, on other hand relationship between social and personal factors of the stress is $r=0.588, p<0.05$ and $r=0.503, p<0.05$ 
respectively. All the relationships are positive and significant. Though the relationship between academic stress factors and academic factors is high and relationship amid environmental factors and performance is weak but there was moderate relationship found between social personal factors and academic performance and thus $\mathrm{H}_{1}$ is accepted. Moreover means core for academic factor is recorded high amongst all i.e. $\mathrm{M}=3.77, \mathrm{~S} . \mathrm{D}=0.57$. Followed by academic performance $\mathrm{M}=3.45, \mathrm{~S} . \mathrm{D}=0.56$, and environmental factor $\mathrm{M}=3.41, \mathrm{~S} . \mathrm{D}=0.63$, the lowest mean score is for personal factors $\mathrm{M}=2.97, \mathrm{~S} . \mathrm{D}=0.70$ respectively. The relationships among variables are in line with previous findings Kotter et al (2017) reported positive and significant association between variables.

Table 3

Regression Analysis

\begin{tabular}{|c|c|c|c|c|c|c|c|}
\hline DV & IV & $\mathrm{R}$ & $\mathrm{R} 2$ & $\beta$ & $\mathrm{F}$ & $\mathrm{t}$ & $\mathrm{p}$ \\
\hline \multirow{5}{*}{$\begin{array}{l}\text { Academic } \\
\text { Performance }\end{array}$} & Constant & 0.985 & 0.97 & & 1654.202 & & 0.000 \\
\hline & Academics & & & 0.926 & & 61.894 & 0.000 \\
\hline & Environmental & & & 0.027 & & 1.804 & 0.073 \\
\hline & Social & & & 0.062 & & 3.664 & 0.000 \\
\hline & Personal & & & 0.021 & & 1.310 & 0.192 \\
\hline
\end{tabular}

The above table 3 presented results of regression analysis. Model fitness i.e. goodness of fit is found significant $\mathrm{F}=1654.202$, $\mathrm{p}<0.01$. This means that regression equation is best fit. $\mathrm{R}$ square is 0.97 i.e. $97 \%$ variance is explained by the four factors upon academic performance. Further analysis of results revealed that beta value of academic factors $\beta=0.926, p<0.01$, this means that one unit change in academic factors could bring $92.6 \%$ variation in the performance of students. Secondly, $\beta=0.027, p>0.05$ this implies that one percent change in environmental factors could bring $2.7 \%$ change in performance and it is not significant change. Third $\beta=$ $0.062, \mathrm{p}<0.01$ means that one unit change in the social factors could bring $6.2 \%$ change in academic performance of students, while $\beta=0.021, p>0.05$ explains that no significant change could be possible in academic performance due to personal factors. Therefore, H2 is partially accepted.

\section{DISCUSSION}

The aim of existing study is to investigate impact of factors of stress upon students' academic performance. For this purpose cross sectional design survey was conducted form students of one public and private sector universities. Total 210 students have participated in the current study. Four factors of stress i.e. academics, social, personal and environmental were selected for current study. While academic performance was measured on basis of results in percentage or CGPA. It was found that all the factors have significant relationship with each other as well as with the academic performance but only two factors have significant impact upon academic performance, academic and social factors. These factors plays very important role in effecting performance of students. The personal and environmental factors needs much attention of the stakeholders i.e. teachers and parents. We need to focus on those factors as they are part of the academic institutions and student's academic life. Students passed over different stages during their academics. They face lot of social financial, economic problems. Students' needs proper guidance and counseling from faculty members it will help them to overcome their problems 
and solve performance issues. They need moral support from parents and attention from faulty members.

The most dominant factors among all four were academic factor on the basis of beta value. It means too much busy schedule, too much work load, inadequate learning facilities and computer labs library issues. Problems faced by students for preparing assignments, presentations and group tasks, lack of interest in few subjects, language barriers may cause the reduction in academic performance of students. The findings of the current study are in line with findings of (Agolla \& Angori, 2009). An environmental factor include no vacations, transport problems, long distance from university to home, were reason of low academic performance. The findings of this study are in line with findings (Fairbrother \& Warn, 2003). Personal factors includes pressure from family and relatives, nervousness while presenting projects and participating in class, low economic condition of the family has impact upon academic performance of study. The findings got support from past study of (Topper, 2007). The findings are consistent with the findings of previous studies of Pascoe, Hetrick and Parker (2019) claimed that students' motivation could be reduced or due to stress there might be increase in school dropout. Also social factors have some role upon increasing and decreasing the academic performance of students.

The co-education, teacher of opposite gender, high expectations form friends, family, parents and relatives have also impact upon academic performance (Albers \& Pattuwage, 2017). Stress leads towards many mental and psychological issues, anxiety, depression and hypertension (Almojali, Almalki, Alothman, Masuadi \& Alaqeel, 2017). Thus, this must be controlled among students so as to enhance their academic performance. Parents, teachers and universities' administration could play important role and arrange meetings at regular intervals to discuss their children issues. The findings of current study got support from previous studies (Albers \& Pattuwage, 2017; Pascoe et al., 2020; Almojali et al., 2017) claimed that stress may lead to several mental, psychological and academic problems. In this connection, keeping in view the existing trends in research, the educational institutes may need to pay attention to good stress management because this system, has the potential to help students to manage their stress throughout their lives.

\section{CONCLUSION}

From the above discussion it is concluded that if students are provided with best computer labs, advance books in the libraries, digital and online excess to e-books, journals and articles, proper time to prepare for assignments, presentations, exams, and quiz may play positive role in enhancing the performance of students. Teachers and parents could play significant role in this matter. Teachers can provide proper guidance and counseling and parents could remove communication barriers, no high expectations for the high grades and good jobs could play effective role. Universities administration, parents and all stakeholders can arrange meetings to discuss students problems related with academics, social, financial, economical and personal factors.

\section{Limitations \& Recommendations}

As the current study was conducted in two universities and the data was collected from small population keeping view this limitation one should be careful in generalizing the findings to other sectors. Second this is cross sectional study researcher must use qualitative methods to 
find in depth understanding of subject matter in future studies. In this connection, sampling technique was convenience, it is recommended that choosing probability sampling technique could be beneficial for the future studies. Add some moderators and mediators to solve more complex problems and models using more sophisticated software like the structural equation modeling.

\section{REFERENCES}

Agolla, J., \& Ongori, H. (2009). An assessment of academic stress among undergraduate students: The case of University of Botswana. Educational Research and Reviews. 4. 063-070.

Albers, B., \& Pattuwage, L. (2017). Implementation in education: Findings from a scoping review. Melbourne: Evidencefor Learning. doi:10.13140/RG.2.2.29187.40483.

Almojali, A. I., Almalki, S. A., Alothman, A. S., Masuadi, E. M., \& Alaqeel, M. K. (2017). The prevalence and association of stress with sleep quality among medical students. Journal of Epidemiology and Global Health, 73, 169-174.

Bhargava, D., \& Trivedi, H. (2018). A Study of Causes of Stress and Stress Management among Youth. IRA-International Journal of Management \& Social Sciences. 11. 108. 10.21013/ jmss.v11.n3.p1.

Britz, J., \& Pappas, E. (2010). "Sources and outlets of stress among university students: Correlations between stress and unhealthy habits." Undergraduate Research Journal for the Human Sciences, 9(1).

Chen, Y., \& Baram, T. Z. (2016). Toward Understanding How Early-Life Stress Reprograms Cognitive and Emotional Brain Networks. Neuropsychopharmacology: official publication of American College of Neuropsychopharmacology, 41(1), 197-206. https: //doi.org/10.1038-/npp.2015.181.

Fairbrother, K., \& Warn, J. (2003). Workplace dimensions, stress and job satisfaction. Journal of Managerial Psychology, 18(1), 8-21. https://doi.org/10.1108/02683940310459565.

Field, A. (2013) Discovering Statistics Using IBM SPSS Statistics: And Sex and Drugs and Rock "N" Roll, 4th Edition, Sage, Los Angeles, London, New Delhi.

Hamaideh, S. (2011). Stressors and Reactions to Stressors Among University Students. The International journal of social psychiatry, 57. 69-80. 10.1177/0020764010348442.

Harris, M., Wilson J. C., \& Hughes S. (2018) Perceived stress and well-being in UK and Australian dental hygiene and dental therapy students. European Journal of Diverse Education, 22: e602-11.

Hussein, A., Alhareth \& Abu-Salih, Muhammad \& Saket, Lubna. (2016). Impact of Job Stress on Job Performance among the Employees of Jordan. 2016. 1-9.

Kotter, T., Wagner, J., Bruheim, L., \& Voltmer, E. (2017). Perceived Medical School stress of undergraduate medical students predicts academic performance: An observational study. BMC Medical Education, 171, p 256.

Laurence, B., Williams, C., \& Eiland, D. (2009). The Prevalence and Socio-demographic Correlations of Depression, Anxiety, and Stress among a group of university students. Journal of American Health. 58, 94-105.

Lin, X. J., Zhang, C. Y., \& Yang, S. (2020). Stress and its association with academic performance among dental undergraduate students in Fujian, China: a cross-sectional online questionnaire survey. BMC Medical Education, 20, 181. https://doi.org/10.1186 /S12909-020-02095-4. 
Ogden, J. (2004). Stress and illness. In Copyright (C) Jane Ogden 2004 (Ed), Health Psychology: A textbook 3rd edition (251-259). Open University Press McGraw-Hill: New York

Pascoe, M. C., Hetrick, S. E., \& Parker, A. G. (2020) The impact of stress on students in secondary school and higher education, International Journal of Adolescence and Youth, 25:1, 104-112, DOI: 10.1080/02673843.2019.1596823.

Selye H. The Stress of Life. New York: McGraw-Hill Book Company; 1956

Tabachnick, B. G., \& Fidell, L. S. (2007). Using Multivariate Statistics (5th ed.). New York: Allyn and Bacon.

Topper, E. F. (2007). "Stress in the library workplace", New Library World, Vol. 108 No. 11/12, pp. 561-564. https://doi.org/10.1108/03074800710838290.

Wadman, R., Durkin, K., \& Ramsden, G. (2011). Social stress in young people with specific language impairment. Journal of Adolescent, 34(3):421-31. doi: 10.1016/j.adolescence. 2010. 06.010. Epub 2010 Jul 22. PMID: 20650511. 